\title{
O SÍMBOLO, EVOCAÇÃO DO INDIZÍVEL
}

Álvaro Cardoso Gomes

Resumo: Este artigo trata dos diferentes conceitos do símbolo, desde sua acepção mais simples, quando se confunde com o signo, até sua acepção mais complexa, conforme o entendiam os poetas do Simbolismo. Nesse movimento literário, os poetas utilizavam o símbolo visando a acessar uma realidade rica em significados, além do mundo aparente. Desse modo, o caminho para seu desvelamento é sempre indireto, exigindo que o leitor seja uma espécie de iniciado, a fim de que possa decifrar a rede de símbolos que levam à integração entre o homem e o universo. Por meio da análise de poemas de António Nobre e Camilo Pessanha, queremos demonstrar como se dá essa escolha dos símbolos para expressar uma realidade oculta, que se entende como o indizível.

Palavras-chave: Indizível; Signo; Símbolo; Simbolismo.

Abstract: This article deals with different concepts of symbols, from its simplest sense, when confused with the sign, until its most complex sense, as understood by the poets of Symbolism. In this literary movement, poets used the symbol, in order to access a reality rich in meanings, beyond the apparent world. Thus, the path to its unveiling is always indirect, requiring the reader to be kind of initiated, so that he could decipher the symbols network, leading to the integration between man and universe. Through the analysis of António Nobre's and Camilo Pessanha's poems, we want to demonstrate how is this choice of symbols to express a hidden reality, which is understood as the unspeakable.

Keywords: Unspeakable; Sign; Symbol; Symbolism.

Ainda que o símbolo possa fazer parte de qualquer objeto artístico que se preze, só foi utilizado de maneira sistemática nos fins do século XIX, quando da vigência da chamada escola simbolista. Assim, pode-se dizer que esse movimento 
é ostensivamente simbólico, não só pelo fato de promover uma inflação simbólica no campo da poesia e da prosa, mas também por levar a cabo uma intencional renovação dos arsenais simbólicos do passado. Antes de discutir essa renovação empreendida pelos simbolistas, contudo, valeria a pena determinar exatamente o que seria símbolo, conforme o ponto de vista dos linguistas e semióticos e dos autores pertencentes à estética finissecular.

No campo da Linguística e da Semiótica, durante algum tempo, o símbolo foi simplesmente confundido com o signo. Ogden \& Richards (1976, p. 33), por exemplo, em $O$ Significado do Significado, consideram que "entre o símbolo e o referente não existe qualquer relação pertinente a não ser uma indireta, que consiste em seu uso por alguém para representar o referente" e, dessa maneira, dão-lhe um sentido arbitrário. Já Saussure procede a uma diferenciação importante, baseado no princípio da motivação. Para o linguista suíço, o signo é arbitrário, pois não há nele vínculo natural entre significante e significado; já o símbolo "tem como característica não ser completamente arbitrário; ele não está vazio, existe um rudimento de vínculo natural entre o significante e o significado" (SAUSSURE, 1971, p. 81-82). Assim, o conjunto de fonemas da palavra "cadeira" 
poderia ser substituído por outro conjunto de fonemas, sem prejuízo algum para o utente, visto não existir motivação entre a série de fonemas e o significado. ${ }^{1}$ Mas, um símbolo como "cruz" é insubstituível enquanto representação do Cristianismo: Jesus Cristo foi sacrificado nesse instrumento de tortura, portanto, a religião cristã só poderá ser representada pela cruz.

Contudo, esse conceito desenvolvido por Saussure remete-nos a uma visão simplificadora do problema, uma vez que, para o linguista genebrino, o símbolo tem um vínculo convencional e fixo com seu referente. O símbolo concebido pelos simbolistas, por sua vez, era algo mais complexo devido à sua polivalência, o que levou Edmund Wilson a fazer as seguintes considerações:

Os símbolos do Simbolismo têm de ser definidos de maneira algo diversa do sentido dos símbolos comuns - o sentido de que a Cruz, o símbolo da Cristandade ou a Estrela e as Listras o símbolo dos Estados Unidos (...). Os símbolos da escola simbolista são, via de regra, arbitrariamente escolhidos pelo poeta para representar suas ideias; são uma espécie de disfarce de tais ideias (1967, p.21).

1 A ideia da arbitrariedade do signo é bastante atenuada por Umberto Eco, quando o crítico italiano Ihe atribui o princípio da necessidade. Assim, o signo torna-se necessário, "na medida em que é imposto pela língua" (ECO, 1971, p. 114). 
Se a tradição consagrou o símbolo como uma coisa que substitui outra, implicando assim um processo de representação de algo abstrato, espiritual, por algo material (o que pode levá-lo a ser confundido com a própria alegoria), os simbolistas vão além dessa concepção simbólica primária. Inicialmente, porque rejeitam a ideia de que o símbolo possa ser simplesmente uma moeda de troca, uma palavra e/ou imagem que traduz um sentido. 0 símbolo, ao invés de se restringir a uma palavra ou imagem, como acontece no simbolismo tradicional, também pode compreender um conjunto de palavras ou imagens, um verso, uma estrofe e, nos casos mais extremos, todo um poema. Em segundo lugar, entre os simbolistas, o símbolo deixa de ser transparente. Velado, ocluso, obscuro, o símbolo configura-se como autêntica epifania do indizível, ou seja, induz, sugere (sem revelar) algo misterioso que deve necessariamente manter a aura de mistério. Nas palavras de Mallarmé, utilizar-se do símbolo significaria: “Evocar pouco a pouco um objeto para mostrar um estado d'alma, ou inversamente, escolher um objeto e extrair dele um estado d’alma, através de uma série de decifrações" (MALLARMÉ, 1951, p. 868-869). O símbolo seria uma cifra, um índice, espécie de mascaramento de algo que o transcende. Dentro do código linguístico, o poeta procura 
o máximo de informação possível, de modo a provocar os espíritos para levá-los a uma realidade rica em significados, além do aparente e do sensível. Desse modo, o caminho para seu desvelamento é sempre indireto, exigindo que o leitor seja espécie de iniciado, a fim de que possa decifrar a rede de símbolos indiciadores do caminho para a integração com um universo carregado de sentido.

Essa concepção do símbolo provoca o surgimento de novas concepções simbólicas, na medida em que o poeta procura traduzir sensações individualizadas do oculto. 0 símbolo caracteriza-se por intensa motivação, atingindo as dimensões de um ícone. Epifania de um mistério, só será representado por uma forma naturalmente propensa a evocar esse mesmo mistério. Dizer é negar a revelação sugerir, eis o segredo. Em consequência disso, o símbolo torna-se arbitrário em relação aos sistemas simbólicos vigentes e, em muitos casos, colabora para que os poemas se transformem em pequenas eclusas, obscuras cintilações. Não contando com o desenvolvimento lógico de um motivo, às vezes, comportando imagens que se ligam apenas por nexos implícitos, os poemas são espaços privilegiados, dentro dos quais se realiza a magia da integração entre a alma do homem e a alma do mundo. 
Nos limites deste artigo, vamos examinar duas concepções de símbolo a partir do exame de poemas de António Nobre e Camilo Pessanha. A primeira, num soneto como "Ó Virgens que passais ao Sol-poente", concebe o símbolo como forçamotriz, por isso mesmo concentrando-o em palavras-imagens estrategicamente localizadas no texto, com vistas a compor uma "história exemplar", ritualística, capaz de conduzir o ser ao espaço da bem-aventurança. No caso de Pessanha, num poema como "Violoncelo", as palavras-imagens não podem ser compreendidas de maneira isolada, pois elas não têm um significado simbólico em si próprias; pelo contrário, servem para compor uma rede sonora propícia à evocação de um estado de espírito difuso.

\section{O POEMA DE ANTÓNIO NOBRE:}

Ó Virgens que passais ao Sol poente, Pelas estradas ermas a cantar! Eu quero ouvir uma canção ardente, Que me transporte ao meu perdido Lar.

Cantai-me, nessa voz onipotente, O Sol que tomba aureolando o Mar, A fartura da seara reluzente, O vinho, a Graça, a formosura, o luar!

Cantai! cantai as límpidas cantigas! Das ruínas do meu lar desaterrai Todas aquelas ilusões antigas 
Que eu vi morrer num sonho, como um ai...

Ó suaves e frescas raparigas, Adormecei-me nessa voz... Cantai! (1968, p. 150)

O poeta concebe o presente como passagem, elo entre a imagem primordial das Virgens, símbolo do que é puro, do que não foi contaminado pela transitoriedade e a imagem também primordial do Sol poente, símbolo de morte, de esvaziamento da existência. Mais ainda: utilizando-se do clichê metafórico "estradas ermas", António Nobre vê o tempo presente como uma dimensão vazia, despida de sentido. Em oposição a este tempo em crise, o passado, representado pela imagem do Lar, é todo cheio de beleza e plenitude ("formosura", "fartura da seara"). Mas como recuperar o passado, se há entre este e o presente que se escoa o muro do esquecimento? É o passado constituído de lembranças mortas ou vivas? A consciência está propensa a recuperá-las?

Tais questões poderiam ser melhor explicitadas se nos debruçássemos um pouco sobre o problema da memória. Nos fins do século XIX e no início do XX, a questão do tempo suscitou grandes reflexões entre ficcionistas e teóricos. Lembramo-nos aqui de Proust, com Em Busca do Tempo Perdido, e de Bergson, com a obra Matéria e Memória, que 
trataram de modo mais específico do fenômeno da memória e do tempo entendido como duração. Proust, No Caminho de Swann, primeiro volume de sua série romanesca, lança a ideia de que o passado não é algo morto, esquecido, mas, sim, algo vivo, que acompanha nossa existência, encarnando em seres e objetos:

É assim com o nosso passado. Trabalho perdido procurar evocá-lo, todos os esforços da nossa inteligência permanecem inúteis. Está ele oculto, fora do seu domínio e do seu alcance, nalgum objeto material (na sensação que nos daria esse objeto material) que nós nem suspeitamos. Esse objeto, só do acaso depende que o encontremos antes de morrer, ou que não o encontremos nunca (PROUST, 1960, p. 45).

Bergson, por sua vez, teorizou a diferença fundamental entre a "memória voluntária" e a "memória involuntária", aquela nascendo da vontade, da inteligência, esta impondose ao sujeito involuntariamente (1999, p. 65). A "memória voluntária", ao ser deflagrada voluntariamente, faz com que o sujeito possa recuperar, por meio da atividade consciente, conteúdos datados e que têm como baliza pontos de referência mais ou menos explícitos, como datas de aniversários, de efemérides, de acontecimentos históricos. O resultado dessa viagem no tempo, por meio da "memória 
voluntária", é a vivência à distância do passado, que se toma, assim, morto, frio, sem a necessária contaminação do afetivo, absolutamente essencial para que o "eu" se transporte a uma realidade que lhe é cara e que se perdeu de modo irremediável. Já a "memória involuntária", por não depender da vontade do sujeito, não traz até o presente conteúdos do passado já cristalizados pelo tempo; pelo contrário, faz com que o sujeito possa reviver instantes mágicos, impregnados pela afetividade e que, por isso mesmo, não dependem de pontos de referência. Esses momentos mágicos, inefáveis, são vividos quando a consciência deles se apaga, e a distância entre o sujeito e o acontecimento se anula. Para a recuperação dos bens perdidos, portanto, a exemplo de um Proust, o "eupoético" necessita de um estímulo sensorial (o ser ou objeto em que o passado encarnou) e, ao mesmo tempo, necessita desligar-se da ação e entregar-se ao devaneio.

António Nobre encontra, na "canção ardente", o estímulo. A melodia, em seu aspecto sinestésico, realiza a magia de fundir duas sensações básicas, a audição e a visão. A fusão de sensações faz parte do ritual que permite ao poeta a recuperação do passado, não por meio da "memória voluntária", mas, sim, da "involuntária", ou seja, o seu ingresso no mundo passado dá-se por um estímulo sensorial 
ao invés de intelectual. É por isso que ele se entrega passivamente à força da canção, que o "transporta" ao perdido Lar, fonte de regeneração e vida. De outro lado, as virgens que representam as musas, ou se se quiser a deusa Mnemósine, inspiradora do estado propício à recordação, Ihe propiciarão o estado de devaneio. Observe-se que, ao final do soneto, as Virgens acabam por simbolizar a imagem materna, que o embala, para fazer com que ele penetre no mundo dos sonhos: "Adormecei-me nessa voz... Cantai!".

A onipotência da voz acompanha o mergulho do Sol no Mar, o astro simbolizando a entrada do ser no inconsciente, a fonte do primitivo, o reservatório de todas as recordações. $E$, nesse instante de pura magia, acontece a fusão das forças elementares, fogo e água - o Sol "tomba, aureolando o Mar", isto é, o elemento aquático contaminase da qualidade essencial do elemento ígneo e vice-versa. Tem início o processo de ingresso do "eu-poético" num mundo perdido, fora do tempo, mundo este em que tudo se corresponde, em que a alteridade se anula, em que os extremos (a vida e a morte, o principio e o fim, a luz e a treva) se aproximam, criando uma realidade nova, que é o tempo regenerado, recuperado pela força da palavra poética tornada símbolo. É a partir, pois, dessa comunhão 
cósmica que sucessivamente se apresentam as benesses constitutivas do passado: a "fartura da seara reluzente", "o vinho, a Graça", "a formosura", "o luar".

Tais bens não têm propriamente valor individual, pelo contrário, são simbólicos, e giram em torno da palavra "Graça", colocada no centro do verso (e mesmo do poema), como verdadeiro catalisador. À esquerda de "Graça", comparecem "seara" e "vinho" e, à direita, "formosura" e "luar". Os dois primeiros bens têm caráter religioso, pois remetem ao ritual da missa (o pão e o vinho, o corpo e o sangue de Cristo); já os dois últimos remetem a um diferente tipo de ritual, o artístico com a formosura, ligada ao estético, e o luar, representando a inspiração noturna da lua, que modela nossa sensibilidade profunda. Ambos os conjuntos de símbolos convergem para o termo central: a Graça pretendida é a graça religiosa e a graça, sinônimo de beleza, no plano artístico. Em síntese, o poeta deseja recuperar, nesse momento de inspiração mágica, um "estado de graça", sinônimo de plenitude, de totalidade, impossível de ser encontrado na vigília porque, durante esta, a consciência se dá conta de que o tempo corre, destruindo os sonhos, as ilusões. O estado de graça existe tão só nesse tempo sem tempo, tempo original, ab ovo, circular, que nunca se esgota. 
Todavia, o tempo original apenas permanece enquanto durar o apelo sensorial da "canção ardente", enquanto houver o envolvimento sensível do sujeito. A nostalgia das origens alimenta-se de um sonho feito de nada, de um sonho que tem a duração do "ai", reiterado formalmente como espécie de sufixo nos verbos "passar", "cantar", "desaterrar". A interjeição configura a curta duração do sonho e o lamento pela perda dos bens essenciais à existência. Desse modo, se o estado de graça dura como um súbito relâmpago, cabe ao poeta criar o artifício para que a sensação se perpetue além da sensação auditivo-colorida. Por essa razão, o soneto tem estrutura circular - o retorno ao princípio faz com que o poema se assemelhe a um ritual mágico, em que, no início e no fim, tautologicamente, a mesma figura inspiradora é invocada.

Mas a carga simbólica dessa imagem, por sua própria importância e por sua configuração, sofre um processo de enriquecimento. A Virgem-rapariga do campo transformase em Virgem-Musa (Mnemósine) e, fechando o poema, em Virgem-Mãe, aquela que embala o filho com a canção propiciadora de um sonho duradouro, o eterno sonho da criança. Este símbolo tem o condão de se tornar elástico, de se desenvolver dentro do poema, abarcando outros 
sentidos, conforme a emoção do poeta se prolongue. A esse propósito, lembremos que o crítico simbolista Saint Antoine costumava relacionar o símbolo com a sugestão, atribuindo-Ihe caráter alusivo. Mas não só isso: dava a entender também que o poeta criava o símbolo por meio de uma sensação que, ao ser despertada, era ao mesmo tempo "prolongada e reforçada por uma impressão de ordem diferente" (SAINT ANTOINE, Apud MICHAUD, 1969, p. 749). Ora, esse prolongamento da emoção (no caso do poema, uma "imagem íntima”), que tem similaridade com o efeito da duração, tem o condão de fazer multiplicarem-se os sentidos conotativos do texto. A Virgem mutante, à medida que se processa sua transformação imagética, explicita a mudança da emoção do poeta: a melancolia do adulto, suscitada pela visão das Virgens passando ao sol poente, metamorfoseia-se no bem estar da criança embalada no colo da Mãe.

António Nobre utiliza-se do símbolo com vistas a contar verdadeira "história de origens", que tem a força de um ritual ou mesmo uma função terapêutica. A "história de origens" seria uma narrativa exemplar, de caráter mítico, cuja estrutura simples permite sua rápida memorização. Mais ainda: ela tem como elementos constitutivos os símbolos que atuam como catalisadores, que atraem para 
si toda a rede de significados. Segundo Mircea Eliade, "a eficácia terapêutica da encantação reside no fato de que, pronunciada ritualmente, ela reatualiza o Tempo mítico da origem" (ELIADE, 1985, p. 73). É o que realiza António Nobre, servindo-se dos símbolos, que funcionam como verdadeiras balizas no poema: "Virgens" / "Sol-poente", nos extremos do primeiro verso do primeiro quarteto, trocam de posição no primeiro verso do segundo quarteto, mudando para "Sol" e "Mar" (apesar de masculino, é tradicional símbolo materno) e convergem para o símbolo maior de todo o soneto, a palavra "Graça", bem supremo que o poeta almeja.

Em Camilo Pessanha, destacamos seu poema "Violoncelo":

Chorai, arcadas

Do violoncelo!

Convulsionadas, Pontes aladas

De pesadelo...

De que esvoaçam, Brancos, os arcos... Por baixo passam, Se despedaçam, No rio, os barcos,

Fundas, soluçam

Caudais de choro...

Que ruínas, (ouçam)!

Se se debruçam, Que sorvedouro!... 
Trêmulos astros...

Soidões lacustres...

- Lemes e mastros...

E os alabastros

Dos balaústres!

Urnas quebradas!

Blocos de gelo...

- Chorai, arcadas,

Despedaçadas,

Do violoncelo! (1945, p. 103-104)

Pessanha, ao contrário de António Nobre, não concentra a carga simbólica em termos estrategicamente colocados no poema. Termos como "pontes", "ruínas", "barcos" etc., não têm valor simbólico em si: são quase transparentes, e sua conotação oferece-se apenas no plano das evocações sonoras e visuais. Por outro lado, não se pode falar que o poema desenvolve um assunto, que se articula de forma linear, o que, de certa maneira, acontece no poema de Nobre. Em "Violoncelo", há uma atmosfera sugestiva, fazendo com que as imagens se unam por associações sonoras. O caráter essencialmente musical do poema nos levaria a pensar que seu fim é o de liberar uma melodia, com tema e variações. O tema é constituído pelos versos “Chorai, arcadas/Do violoncelo!", evocações no início e no fim do poema, e delas saem as variações, ao mesmo tempo, sonoras e visuais. As sonoras comparecem na 
alternância entre as vogais abertas e fechadas e no jogo consonantal (sibilantes, líquidas, vibrantes). Assim, por exemplo, a continuidade sonora, representando tanto o movimento musical quanto o movimento das águas, é mimetizado (ou iconizado) pelo acúmulo de sibilantes ("por baixo passam/Se despedaçam"), enquanto a ruptura, a quebra, pelas vibrantes e linguodentais ("trêmulos astros...) Soidões lacustres.../- Lemes e mastros.../E os alabastros/Dos balaústres!"). As variações visuais, por sua vez, desdobramse a partir da imagem motriz, que é o violoncelo: as arcadas do violoncelo lembram pontes, cujos arcos (que também remetem ao arco que faz soar o instrumento musical) têm uma relação metonímica e uma relação sonora com os (b) arcos. Repara-se que a imaginação do poeta associou o formato do violoncelo com a ponte e mesmo com o barco, e tal operação poética serviu para deflagrar um processo evocador de imagens por contiguidade: pontes despertam arcos, que despertam barcos e que, por fim, lembram o rio e todas as demais imagens relacionadas com os elementos aquáticos/náuticos: "caudais de choro", "sorvedouro", "astro", lago ("lacustres"), "lemes", "mastros", "alabastros", "balaústres", "blocos de gelo".

Mas podemos pensar em outro tipo de associação que é puramente musical: a de que os fonemas se comportam 
como autênticas notas musicais, compondo uma espécie de melodia. A melodia nascida do violoncelo evocado no poema desenvolve cinco motivos principais, correspondentes a cada estrofe. O primeiro motivo nasce do adjetivo "convulsionadas" e equivale a um frenesi musical, suscitando, por conseguinte, o "pesadelo" das "pontes aladas", dos barcos despedaçados, do "sorvedouro" etc. O segundo motivo musical, não mais provocado pela convulsão, é calmo, fluido como o rio. O terceiro volta a acentuar a ideia de movimento com o "sorvedouro", sendo que o movimento agora é circular. O quarto movimento, com a imagem lacustre, sugere a calmaria, após a borrasca, a anulação do movimento. Não é à toa que, nessa estrofe, abundem as reticências, as frases nominais, nas quais a ausência do verbo serve para sugerir a estagnação. O último movimento lembra definitivamente o fragmentário, não só com o adjetivo "despedaçadas", mas também com a referência às "urnas quebradas" e aos "blocos de gelo". Essa sequência de motivos musicais é homóloga, no plano visual, à sequência dos motivos aquáticos: "choro", "rio", "sorvedouro", lago e "gelo", pelo fato de que a água tem a fluidez semelhante à da música. Como tal, o elemento aquático presta-se a mimetizar o desenrolar da melodia, a passagem do tempo e a falta de consistência da realidade evocada. Transparência e fluidez são as qualidades 
essenciais de um mundo que se esvai, que se concentra num sorvedouro, sob a forma de ruínas, e que depois emerge nos fragmentos do final do poema.

A conjunção das imagens sonoras e visuais tem a finalidade de suscitar determinado estado de espírito, determinado tipo de sentimento. Os movimentos da melodia correspondem (evocam) movimentos da alma, variáveis conforme a impressão causada pela relação do sujeito com a realidade móbil. O sentimento de dor evocado, similar ao desenrolar da melodia, converge todo para a terceira estrofe do poema, espécie de núcleo, moto-perpétuo musical, a tradução da eterna dor humana, sem fim e sem sentido. Não é à toa que o tanger do instrumento musical seja metaforizado pelo verbo "chorar", que se intensifica à medida que se avolumam as imagens de pesadelo. O choro é então substituído pelas "caudais de choro" - o excesso de dor, a partir daí, provoca como que um esfacelamento do mundo. Observam-se as ruínas, nascidas do sorvedouro e que convergem para o despedaçamento dos dados concretos da realidade: as pontes, os barcos. Restam sinédoques, objetos desirmanados, as imagens funerárias das urnas, a água sem fluidez, solidificada na algidez dos blocos de gelo, o que acarreta a destruição da imagem do próprio violoncelo, pois suas arcadas estão "despedaçadas". Isto quer dizer que 
a água morta (a melodia morta?) é impotente para criar o devaneio: sua qualidade gelada impede o fluir contínuo, o vai-e-vem embalador dos sonhos. O poema fecha-se com imagens mortuárias: a convulsão, que dá início ao processo musical, epilético estado suscitador da loucura visionária, cede lugar ao despedaçamento. Se a convulsão é criadora de movimento, vida latente (ainda que dolorosa) e, portanto, passível de gerar a musicalidade, o despedaçar nada cria, porque, destroçado o violoncelo, torna-se impossível liberar qualquer melodia que seja.

A série de associações a que fizemos referência ao longo da leitura do poema estabelece-se a partir das imagens visuais e musicais ligadas entre si e capazes de despertar sentimentos e/ou sensações. Podemos, assim, pensar que constituiriam a "emoção prolongada", tal qual a concebia Saint Antoine. Contudo, a ideia de símbolo em Pessanha não se esgota tão só nas imagens que evocam um ou mais estados de espírito, porquanto todo o poema vale como um símbolo maior, ou seja, o poema é o violoncelo, atua como verdadeiro ícone desse instrumento musical. A disposição vertical das estrofes mimetiza o corpo do instrumento, inclusive nas aberturas em forma de ff sobre o tampo harmônico, e as quatro sílabas de cada verso representam as quatro cordas do violoncelo, a serem tangidas pelo arco. Já a estrofe de cinco versos 
pode ser uma representação do pentagrama a ser lido pela voz-arco que faz soar o instrumento. Resulta daí que, similar ao instrumento musical que provoca pesadelos por meio de determinada melodia, o poema provoca pesadelos semelhantes por meio da música das palavras. Nesse caso, o arco que tange as cordas, na horizontal, tem analogia com a voz que enuncia cada verso, fundindo os fonemas, como acontece com as notas numa frase musical, mas por meio da aliteração, do eco, da assonância etc.

Concluindo: se António Nobre faz seu soneto girar em torno de termos nucleares, verdadeiros catalisadores de sentido, o mesmo não acontece com Pessanha, pois o autor de Clepsidra prefere trabalhar com associações melódicas, em que as palavras-notas musicais quase se evaporam para compor a rede sonora. Apesar dessa diferença fundamental quanto à compreensão do símbolo (talvez venha daí a sua arbitrariedade em relação às convenções simbólicas), há um ponto em comum entre ambos os poetas: António Nobre e Camilo Pessanha preferem a via indireta da expressão de determinados estados de espírito. O estado de Graça e o sentimento de Dor não se manifestam por meio de um discurso claro, objetivo. Muito pelo contrário, são apenas evocados com o auxílio da imagem, ora auditiva - as amarrações internas dos fonemas ou das palavras entre si, a 
carga sonora de cada verso e a circularidade do conjunto de estrofes -, ora visual - os objetos suscitados, as colorações, a luminosidade, a opacidade. Tais recursos constituiriam o "mascaramento" aludido de início, cujo fim é não apenas ocultar algo misterioso, mas também propiciar ao leitor os meios de ele exercer uma tarefa evocativa. Assim, tais poemas minimizam a atuação intelectual em prol de uma atuação essencialmente sensorial. Os poemas não visam a liberar um conteúdo intelectual: funcionam como índice de uma realidade oculta (o estado de Graça, o sentimento de Dor), apenas perceptível pela manipulação adequada dos símbolos. Perceptível e jamais apreensível diretamente como um conteúdo explícito, visto que o símbolo, reiterando o que já dissemos, nada mais é que uma epifania do indizível.

\section{REFERÊNCIAS}

Bergson, H. (1999). Matéria e Memória. São Paulo: Martins Fontes.

Eco, U. (1971). Obra Aberta (2a ed.). São Paulo: Perspectiva.

Eliade, M. (1985). Le sacré et le profane. Paris: Gallimard.

Mallarmé, S. (1951). Oeuvres poétiques complètes. Paris: Gallimard.

Nobre, A. (1968). Só. Coimbra: Tavares Martins.

Ogden \& richards. (1976). O Significado do Significado (2a ed.). Rio de Janeiro: Zahar.

Pessanha, C. (1945). Clepsidra. Lisboa: Ática.

Proust, M. (1960). Em Busca do Tempo Perdido (2a ed. Vol. 7). Rio de Janeiro: Globo. 
Saint Antoine (1979). L'hermitage. In Guy Michaud. Méssage poétique du Symbolisme. Paris: Nizet.

Saussure, F. (1971). Curso de Linguística Geral (3a ed). São Paulo, Cultrix.

Wilson, E. (1967). O Castelo de Axel. São Paulo: Cultrix.

Álvaro Cardoso Gomes é Professor Titular da USP e Coordenador do Mestrado Interdisciplinar em Ciências Humanas da UNISA. Publicou, entre outras obras, livros de ensaio - A Melodia do Silêncio, A Estética Simbolista, Alçapão de Imagens - e romances - Os rios Inumeráveis, Concerto Amazônico. Contato: acgomes@unisa.br, alcgomes@uol. com.br. 